\title{
Assessment of exposure to methylmercury in pregnant Japanese women by FFQ
}

\author{
Kozue Yaginuma-Sakurai ${ }^{1, *}$, Miyuki Shimada ${ }^{1}$, Takashi Ohba ${ }^{1}$, Kunihiko Nakai $^{1}$, \\ Keita Suzuki ${ }^{2}$, Naoyuki Kurokawa ${ }^{1}$, Satomi Kameo ${ }^{1}$ and Hiroshi Satoh ${ }^{1}$ \\ 'Department of Environmental Health Sciences, Tohoku University Graduate School of Medicine, \\ 2-1 Seiryo-machi, Aoba-ku, Sendai 980-8575, Japan: ${ }^{2}$ Department of Human Development, Tohoku University \\ Graduate School of Education, Sendai, Japan
}

Submitted 21 April 2008: Accepted 18 December 2008: First published online 6 April 2009

\begin{abstract}
Objective: To examine whether an FFQ can be used for assessing exposure to methylmercury $(\mathrm{MeHg})$ by estimating $\mathrm{MeHg}$ intake from seafood consumption using the FFQ and confirming the accuracy of the estimated value.

Design: Seafood consumption of pregnant women was assessed using the FFQ. Total mercury (T-Hg) concentrations of maternal red blood cells (RBC) and hair were measured as exposure indices of $\mathrm{MeHg}$

Setting: A prospective birth cohort study, the Tohoku Study of Child Development (TSCD), which has been ongoing since 2001.

Subjects: The subjects were 609 pregnant Japanese women who were enrolled in the TSCD.

Results: MeHg intake was estimated from seafood consumption determined using the FFQ and the MeHg concentrations in each type of seafood. The accuracy of the estimated value was confirmed by comparison with $\mathrm{T}-\mathrm{Hg}$ in $\mathrm{RBC}$ and hair. Estimated $\mathrm{MeHg}$ intake was $42.3 \mu \mathrm{g}$ /week, and $43.0 \%$ of that was from large predatory fish. Compared with the Japanese tolerable weekly intake, in total $12.5 \%$ of the subjects exceeded it. T-Hg concentrations in RBC and hair were significantly correlated with estimated MeHg intake: $r=0.325(P<0 \cdot 0001)$ for RBC and $r=0.305(P<0 \cdot 0001)$ for hair.

Conclusions: Estimated MeHg intake based on the FFQ was significantly associated with $\mathrm{T}-\mathrm{Hg}$ concentrations in RBC and hair. Although the estimated value involves uncertainties, the FFQ appears to be a useful tool for assessment of exposure to MeHg.
\end{abstract}

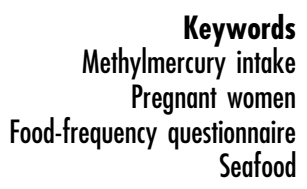

Methylmercury $(\mathrm{MeHg})$ is a well-known environmental neurotoxicant. Since $\mathrm{MeHg}$ readily crosses the placenta, fetuses are a high-risk group for $\mathrm{MeHg}$ exposure. A delay of development of cognitive function in children caused by prenatal MeHg exposure was shown in some epidemiological studies ${ }^{(1-3)}$. Therefore, there has been concern about $\mathrm{MeHg}$ exposure during pregnancy. To minimize the risks of adverse effects of $\mathrm{MeHg}$, several thresholds of safety have been proposed; e.g. a provisional tolerable weekly intake (PTWI) ${ }^{(4)}$, a reference dose (RfD) ${ }^{(5)}$ and a minimal risk level ${ }^{(6)}$. In Japan, the tolerable weekly intake (TWI) for MeHg of $2 \cdot 0 \mu \mathrm{g} / \mathrm{kg}$ body weight per week for pregnant and potentially pregnant women was proposed by the Japan Food Safety Commission ${ }^{(7)}$.

Assessment of exposure to $\mathrm{MeHg}$ usually has been conducted using biomarkers such as blood and hair ${ }^{(8)}$. As the source of $\mathrm{MeHg}$ exposure is mostly seafood because of food chain transfer, it might be possible to conduct exposure assessment by estimating $\mathrm{MeHg}$ intake from seafood consumption. If we can conduct such assessment using a dietary survey, it will have the following merits. There will be no need to collect biological samples. Rapid assessment on the spot will be possible, because there is no need for chemical analysis. It will also be possible to conduct dietary guidance during pregnancy at the same time.

It is known that the biological half-life of $\mathrm{MeHg}$ in man is $70 \mathrm{~d}^{(8)}$. Therefore, long-term dietary intake data are needed to assess the chronic dietary exposure to $\mathrm{MeHg}$ from seafood. There are highly accurate dietary survey methods available such as duplicate meals and dietary records, but it is difficult to continue a survey for a long time by these methods. In this respect, the FFQ is one reasonable survey method for assessing $\mathrm{MeHg}$ exposure because it can obtain information about eating patterns over a longer period with a simple questionnaire ${ }^{(9,10)}$. 
The FFQ is commonly used in epidemiological studies in different contexts, groups and populations ${ }^{(11,12)}$.

We have been performing a prospective birth cohort study, the Tohoku Study of Child Development (TSCD), since 2001 to examine the effects of perinatal exposure to $\mathrm{MeHg}$ and persistent organic pollutants on child development, in which an FFQ was used to assess the food intake for pregnant women and maternal blood and hair were collected to determine the level of exposure to $\mathrm{MeHg}^{(13)}$. In the present study, we estimated the $\mathrm{MeHg}$ intake from seafood consumption based on the FFQ and confirmed the accuracy of the estimated value by comparison with biomarkers to examine whether the FFQ can be used for assessment of exposure to $\mathrm{MeHg}$.

\section{Methods}

\section{Study design}

From January 2001 until September 2003, a total of 687 pregnant women who were in the 22nd to 28th week of pregnancy were enrolled in the TSCD and eligible for inclusion (i.e. no severe diseases such as thyroid dysfunction, hepatitis, immune deficiency, malignant tumours and mental diseases; no in vitro fertilization; and Japanese as their native language). The study was carried out with their informed consent and approval of the Ethics Committee of Tohoku University Graduate School of Medicine.

Information on characteristics of the subjects including age, body weight and height before pregnancy, smoking and alcohol consumption during pregnancy, and education was collected by self-administered questionnaires at enrolment or $4 \mathrm{~d}$ after delivery. Blood samples were collected at the 28th week of pregnancy using a vacuumsystem heparin tube. Collected peripheral blood $(30 \mathrm{ml})$ was centrifuged within $4 \mathrm{~h}$ for $20 \mathrm{~min}$ at $3000 \mathrm{rpm}$, and then red blood cells (RBC), plasma and whole blood were stored at $-80^{\circ} \mathrm{C}$. Hair samples were collected at $4 \mathrm{~d}$ after delivery. The hair was cut next to the scalp, in the occipital area, with stainless steel scissors. The hair samples were placed in a plastic bag and kept in a desiccator. The FFQ was conducted $4 \mathrm{~d}$ after delivery.

\section{Estimation of methylmercury intake based on the FFQ}

The FFQ was conducted by trained interviewers who showed the subjects full-scale pictures of seafood dishes ${ }^{(14)}$. The subjects gave the frequency and portions of consumption over the past year according to each picture. The amounts of consumption were calculated from the frequencies and the portions given by the subjects individually. We selected several kinds of seafood that were often found at the fish market in the study area and classified them into thirteen items: i.e. large predatory fish (such as tuna, swordfish and marlin), bonito, whale, salmon, eel, yellowtail, silvery blue fish, white-meat fish, other fish, squid, shellfish, salmon roe and canned tuna, considering MeHg level and type of seafood. It is thought that these thirteen items cover almost all fish/ shellfish consumed in this area. Because shark is rarely consumed in this area, we did not include shark in the thirteen items.

To estimate the MeHg intake, a calculation was performed, multiplying the amount of each of the thirteen items of seafood consumption ( $\mathrm{g} /$ week) obtained from the FFQ by the total mercury (T-Hg) concentration in that item $(\mu \mathrm{g} / \mathrm{g})$. The T-Hg concentrations in the items were obtained from a database maintained by the Japan Ministry of Health, Labor and Welfare ${ }^{(15)}$. This database was constructed based on the data of T-Hg and $\mathrm{MeHg}$ concentrations in 385 kinds and 9712 samples of seafood surveyed in Japan. It contains the MeHg concentrations in some, but not all kinds of seafood. The number of samples for MeHg listed is not sufficient compared with the number of samples for T-Hg. Therefore we did not use the data for MeHg but used the data for T-Hg instead. It has been suggested that MeHg comprises $>90 \%$ of the T-Hg in seafood ${ }^{(16,17)}$; thus we assumed that the amount of MeHg was $100 \%$ of the T-Hg concentration in the items in order to prevent underestimation.

\section{Determination of total mercury in biological samples}

We used RBC and hair as the exposure indices of MeHg based on evidence that more than $90 \%$ of $\mathrm{T}-\mathrm{Hg}$ in RBC and hair is $\mathrm{MeHg}^{(18)}$. It has been reported that permanent waving decreases the mercury concentration in hair ${ }^{(19,20)}$, but Ohba et al. ${ }^{(21)}$ reported that the average mercury concentration of 3 -cm segments of hair from the proximal end showed no significant decrease by permanent waving. In our cohort, $21 \cdot 2 \%$ of the subjects had permanent waving or straightening. Therefore we used $3-\mathrm{cm}$ segments from the proximal end, which provided an accurate exposure level.

$\mathrm{T}-\mathrm{Hg}$ in RBCs and hair were determined by cold vapour atomic absorption spectrophotometry according to the method of Akagi and Nishimura ${ }^{(22)}$. Each sample was acid digested with $\mathrm{HNO}_{3}, \mathrm{HClO}_{4}$ and $\mathrm{H}_{2} \mathrm{SO}_{4}$ at $200^{\circ} \mathrm{C}$ for $30 \mathrm{~min}$. The resultant inorganic mercury was then reduced to mercury vapour by adding $10 \% \mathrm{SnCl}_{2}$ to a flameless atomic absorption monitor (HG-201; Sanso Co., Ltd, Tokyo, Japan). To ensure the accuracy of the determination, whole-blood reference material Seronorm 201605 (SERO, Billingstad, Norway) and human hair reference material NIES CRM No. 13 (National Institute of Environmental Studies, Tukuba, Japan) were used.

\section{Statistical analysis}

The estimated $\mathrm{MeHg}$ intake and the T-Hg concentrations in RBC and hair were not normally distributed. The associations of estimated $\mathrm{MeHg}$ intake with T-Hg concentrations in RBC and hair were analysed using Pearson's correlation 
coefficient $(r$ ) after logarithmic transformation. One-way ANOVA was conducted for evaluation of the differences among T-Hg concentrations in RBC and hair by quartile of estimated $\mathrm{MeHg}$ intake. This analysis was also performed after logarithmic transformation of $\mathrm{T}-\mathrm{Hg}$ concentrations in RBC and hair. All statistical analyses were carried out using the JMP software package version $7 \cdot 0$ (SAS Institute Inc., Cary, NC, USA).

\section{Results}

\section{Characteristics of the subjects}

Six hundred and nine pregnant women enrolled in the TSCD who donated blood and hair and completed the FFQ were included in the present analysis. The characteristics of these 609 women are shown in Table 1. Mean (SD) age was 31.5 (4.4) years. The mean (SD) weight, height and BMI before pregnancy were $52 \cdot 6(7 \cdot 6) \mathrm{kg}$, $158.6(4.9) \mathrm{cm}$ and $20 \cdot 9(2 \cdot 7) \mathrm{kg} / \mathrm{m}^{2}$, respectively. During pregnancy, $7 \cdot 2 \%$ of the subjects smoked and $32 \cdot 3 \%$ consumed alcohol. Seventy-five per cent of the subjects had $>12$ years of education.

The distributions of $\mathrm{T}-\mathrm{Hg}$ concentrations in RBC and hair are shown in Fig. 1. The median (5th, 95th percentile) T-Hg concentration was $13 \cdot 1(5 \cdot 8,27 \cdot 6) \mathrm{ng} / \mathrm{g}$ for RBC and $2 \cdot 0(0 \cdot 9,4 \cdot 4) \mu \mathrm{g} / \mathrm{g}$ for hair. There was a significant correlation between $\mathrm{T}-\mathrm{Hg}$ concentrations in $\mathrm{RBC}$ and hair (Pearson's correlation coefficient after log-transformation: $r=0 \cdot 916, P<0 \cdot 0001$; data not shown).

\section{Estimated methylmercury intake based on the FFQ}

The frequencies and amounts of consumption and estimated $\mathrm{MeHg}$ intake for the thirteen items are shown in Table 2. In total, the median (5th, 95th percentile) frequency of consumption was $5 \cdot 4(1 \cdot 9,12 \cdot 6)$ times/week and amount was $309 \cdot 7(93 \cdot 1,742 \cdot 5) \mathrm{g} /$ week. The most frequently consumed item was salmon (mean of the ratio to total consumption for all subjects: $17 \cdot 6 \%$ ), followed by silvery blue fish $(14 \cdot 7 \%)$, canned tuna $(11 \cdot 3 \%)$ and white-meat fish $(10 \cdot 7 \%)$. Silvery blue fish was the most consumed item in terms of amount (17.7\%), followed by white-meat fish (15.6\%), large predatory fish (13.5\%) and salmon $(11 \cdot 8 \%)$. Whale was rarely consumed. Median (5th, 95th percentile) total MeHg intake was estimated to be $42 \cdot 3(8 \cdot 8,134 \cdot 0) \mu \mathrm{g} /$ week. Large predatory fish were the principal source of $\mathrm{MeHg}(43 \cdot 0 \%)$, followed by whitemeat fish (12.7\%) and silvery blue fish (11.3\%). Every other item had a contribution of less than $10 \cdot 0 \%$. Dividing the total MeHg intakes ( $\mu \mathrm{g} /$ week) by the body weights of individuals measured before pregnancy, the median (5th, 95th percentile) $\mathrm{MeHg}$ intake was calculated to be $0 \cdot 8(0.2,2 \cdot 6) \mu \mathrm{g} / \mathrm{kg}$ body weight per week. The distribution of $\mathrm{MeHg}$ intake per kilogram of body weight per week is shown in Fig. 2. It was found that $12.5 \%$ of the subjects exceeded the TWI.
Table 1 Characteristics of the study subjects: 609 pregnant Japanese women enrolled in the Tohoku Study of Child Development

\begin{tabular}{lrrr}
\hline & Mean & SD & $\%$ \\
\hline Age (years) & $31 \cdot 5$ & $4 \cdot 4$ & \\
Weight $(\mathrm{kg})$ & $52 \cdot 6$ & $7 \cdot 6$ & \\
Height $(\mathrm{cm})$ & $158 \cdot 6$ & $4 \cdot 9$ & \\
BMl $\left(\mathrm{kg} / \mathrm{m}^{2}\right)$ & $20 \cdot 9$ & $2 \cdot 7$ & \\
Smoking during pregnancy & & & $7 \cdot 2$ \\
Alcohol consumption during pregnancy $^{\text {Education }(>12 \text { years) }}{ }^{*}$ & & & $32 \cdot 3$ \\
\hline
\end{tabular}

${ }^{*}$ Data were missing for two subjects.
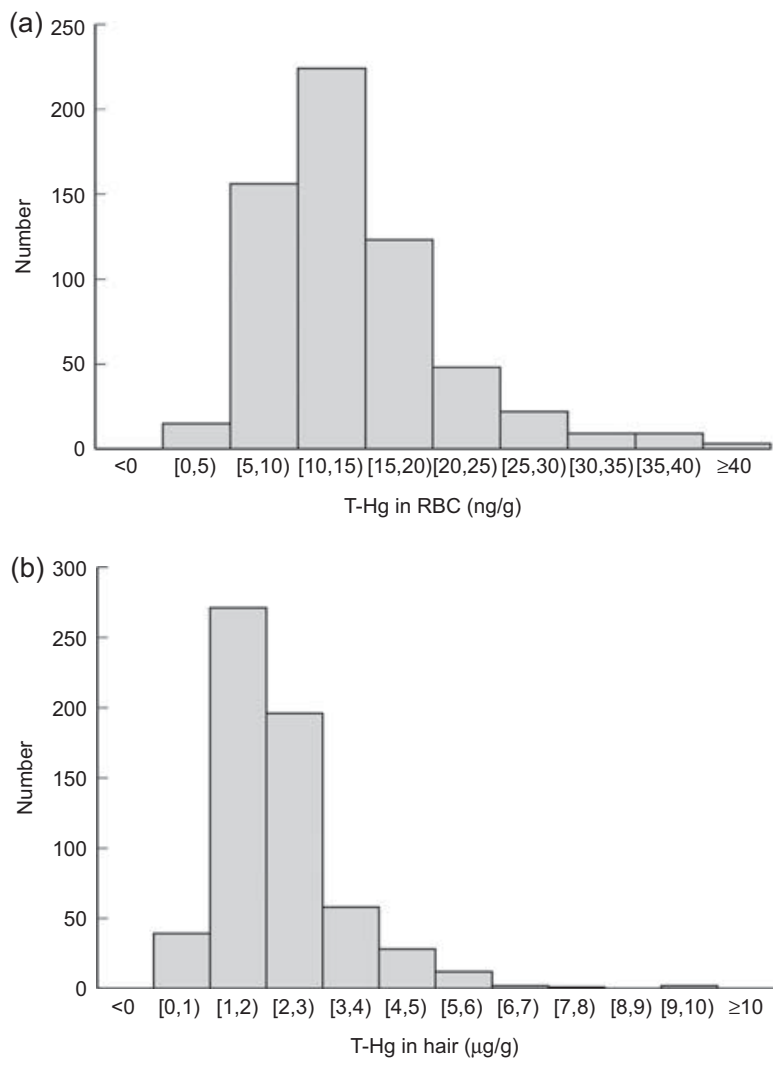

Fig. 1 Distributions of total mercury $(\mathrm{T}-\mathrm{Hg})$ concentrations in red blood cells (RBC) (a) and hair (b) in 609 pregnant Japanese women enrolled in the Tohoku Study of Child Development. The median (5th, 95th percentile) of $\mathrm{T}-\mathrm{Hg}$ concentration is $13.1(5 \cdot 8,27 \cdot 6) \mathrm{ng} / \mathrm{g}$ for RBC and $2.0(0.9$, 4.4) $\mu \mathrm{g} / \mathrm{g}$ for hair

\section{Association of methylmercury intake with total mercury in red blood cells and bair}

The $\mathrm{T}-\mathrm{Hg}$ concentrations in $\mathrm{RBC}$ and hair were significantly correlated with the estimated $\mathrm{MeHg}$ intake: $r=0.325(P<0.0001)$ for RBC, $r=0.305(P<0 \cdot 0001)$ for hair (Fig. 3). The T-Hg concentrations in RBC and hair by quartile of $\mathrm{MeHg}$ intake are shown in Table 3. As the $\mathrm{MeHg}$ intake increased, the T-Hg concentrations in RBC and hair increased significantly $(P<0.0001$ for RBC, $P<0 \cdot 0001$ for hair). 


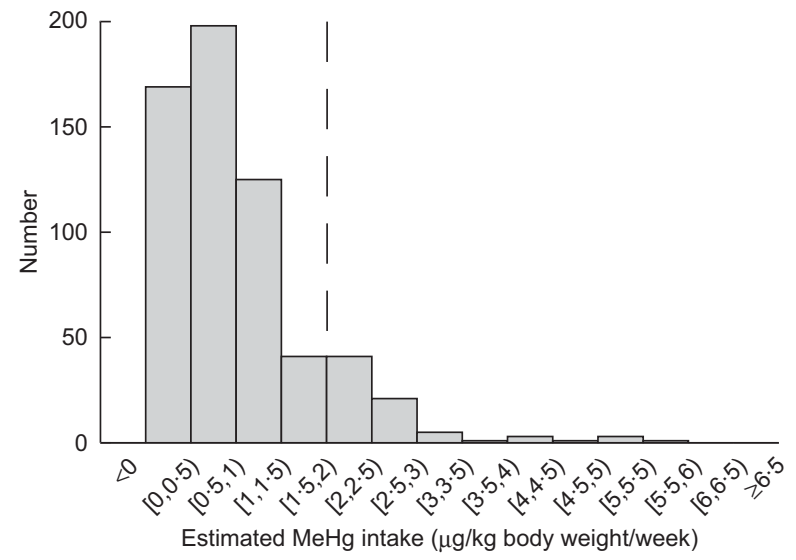

Fig. 2 Distribution of estimated methylmercury ( $\mathrm{MeHg}$ ) intake in 609 pregnant Japanese women enrolled in the Tohoku Study of Child Development. The median (5th, 95th percentile) of $\mathrm{MeHg}$ intake is $0.8(0.2,2.6) \mu \mathrm{g} / \mathrm{kg}$ body weight per week. The broken line indicates the Japanese tolerable weekly intake of $2.0 \mu \mathrm{g} / \mathrm{kg}$ body weight per week

\section{Discussion}

In the present study, the MeHg intake was estimated to be $42 \cdot 3 \mu \mathrm{g} /$ week (median), and nearly half of it was taken from large predatory fish such as tuna, swordfish and marlin. Tuna, a popular fish in Japan, is often eaten as 'sashimi' and 'sushi', and it has been reported that about one-third of the catch of tuna in the whole world is provided for Japan ${ }^{(23)}$. In our study subjects, the large predatory fish consumption was also relatively high as shown Table 2 . It was found that $12.5 \%$ of the subjects exceeded the Japanese TWI ${ }^{(7)}$ (Fig. 2). Additionally, considering the PTWI of $1.6 \mu \mathrm{g} / \mathrm{kg}$ body weight per week proposed by the Joint FAO/WHO Expert Committee on Food Additives $^{(4)}$ and the RfD of $0 \cdot 1 \mu \mathrm{g} / \mathrm{kg}$ body weight per $\mathrm{d}$ proposed by the US Environmental Protection Agency $^{(5)}, 17 \cdot 4 \%$ and $57 \cdot 5 \%$ of our study subjects exceeded these reference points, respectively. Worldwide, the seafood consumption of our country is definitely not high ${ }^{(23)}$, and the level of exposure to $\mathrm{MeHg}$ in our study subjects was not high compared with other studies ${ }^{(1-3,24,25)}$. Nevertheless, there was a group highly exposed to MeHg. Total seafood consumption of the subjects who exceeded the TWI was higher than for other subjects, and large predatory fish consumption, especially, was higher (Student's $t$ test: $P<0 \cdot 0001$; data not shown). From these results, it could be thought that large predatory fish such as tuna, swordfish and marlin are the main sources of exposure to $\mathrm{MeHg}$ in the Japanese.

On the other hand, although containing MeHg, seafood is part of a nutritious diet and a good source of $n$-3 PUFA which are known to be beneficial for the brain in fetal development. In contrast to several studies ${ }^{(1-3)}$, no consistent pattern of adverse effects of prenatal $\mathrm{MeHg}$ exposure was found in others such as the Seychells 
study $^{(24,25)}$, which focused on nutrients in fish $^{(26,27)}$. Another large epidemiological study has also suggested the benefits of seafood intake ${ }^{(11)}$. If pregnant women
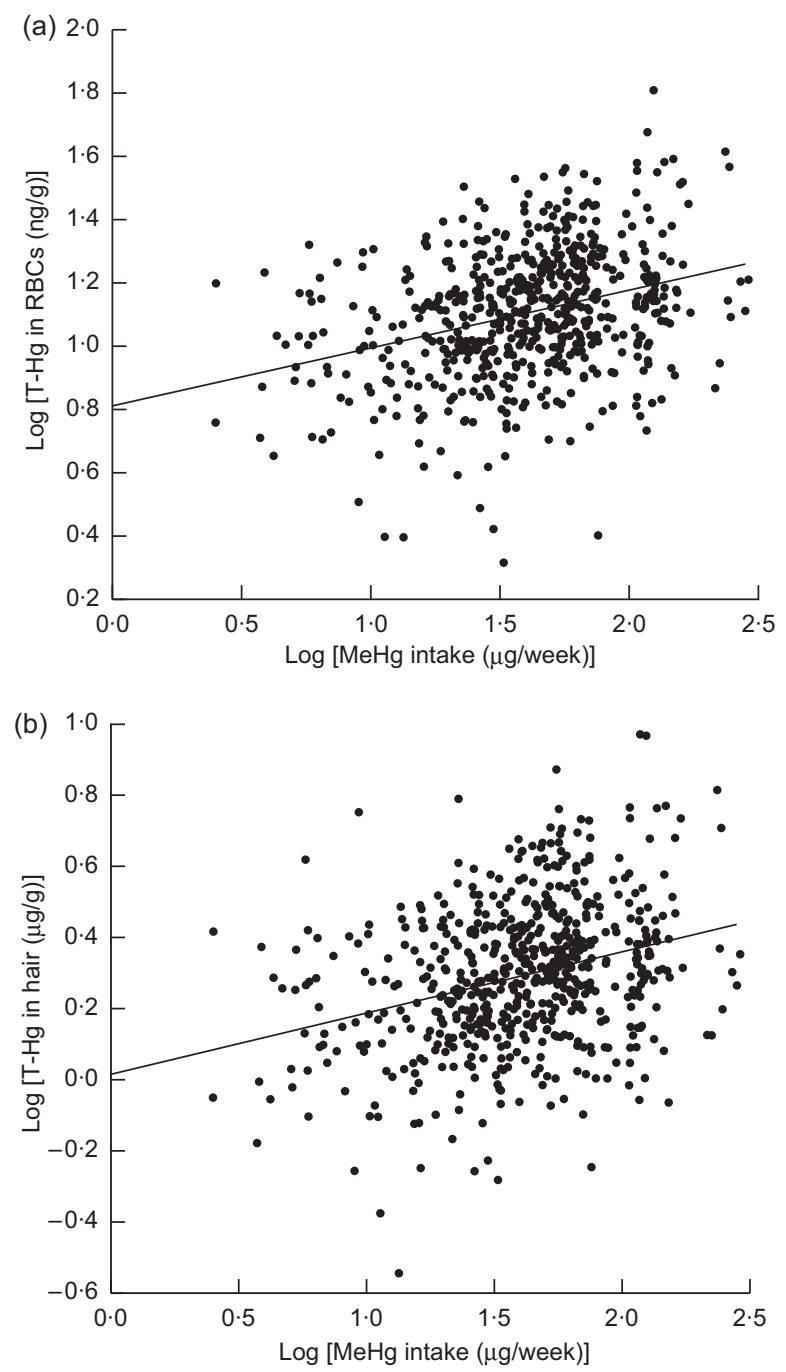

Fig. 3 Correlations between estimated methylmercury (MeHg) intake and total mercury $(\mathrm{T}-\mathrm{Hg})$ concentrations in red blood cells (RBC) (a) and hair (b), after log transformation, in 609 pregnant Japanese women enrolled in the Tohoku Study of Child Development. (a) MeHg intake and T-Hg in RBC (ng/g): $Y=0.805+0.187 X(r=0.325, P<0.0001)$. (b) MeHg intake and $\mathrm{T}-\mathrm{Hg}$ in hair $(\mu \mathrm{g} / \mathrm{g}): Y=0.016+0.175 X \quad(r=0.305$, $P<0.0001)$ excessively restrict seafood consumption to lessen $\mathrm{MeHg}$ intake, there will be a shortage of nutritious substances such as $n$-3 PUFA. Adverse effects of MeHg may depend on the balance between $\mathrm{MeHg}$ and beneficial nutritional components in the seafood consumed ${ }^{(28)}$.

The main objective of the present study was to confirm the accuracy of the estimated value for $\mathrm{MeHg}$ by comparison with biomarkers. The correlation coefficients of the estimated values for T-Hg in RBC and hair were 0.325 $(P<0.0001)$ and $0.305(P<0.0001)$, respectively. In other studies, Sanzo et al. ${ }^{(29)}$ reported that the correlation coefficient between $\mathrm{T}-\mathrm{Hg}$ intake and T-Hg in RBC for 120 individuals in Spain was $0.36(P<0.005)$, Iwasaki et $a l .{ }^{(30)}$ reported one of $0.335(P<0.001)$ between $\mathrm{T}-\mathrm{Hg}$ intake and $\mathrm{T}-\mathrm{Hg}$ in hair for 154 Japanese women, and Ohno et al. ${ }^{(31)}$ reported a correlation coefficient of 0.551 $(P<0 \cdot 01)$ between T-Hg intake and T-Hg in hair for fiftynine Japanese women. Although the sample sizes and significance levels were different among studies, our result of 'about $0 \cdot 3$ ' was similar to the former two studies.

There are several factors that influence the association between estimated intake values and biomarkers. The first is the uncertainty of the dietary survey method, i.e. the FFQ. Although validity of the information collected by FFQ has been shown by many validation studies ${ }^{(9,10)}$, this information is not as detailed as that collected by dietary records because it involves a recall bias ${ }^{(32)}$. It has been reported that the FFQ has a tendency of overestimate when there are many food items, and underestimate when there are few food items, compared with a dietary record $^{(32)}$. In the present study, from the large positive intercepts and gentle slopes in Fig. 3, it was found that $\mathrm{MeHg}$ intake had a tendency to be overestimated at lower exposure levels and underestimated at higher exposure levels. Another factor is the uncertainty of the database on mercury concentrations in seafood. Iwasaki et al.(30) reported that the average amount of estimated $\mathrm{T}-\mathrm{Hg}$ intake determined using the FFQ was $15 \cdot 3 \mu \mathrm{g} / \mathrm{d}$ (geometric mean), although they used a different database ${ }^{(33,34)}$ from the one used in our study for calculation. This estimated value is about 2.5 times higher than our result. If the exact amount of seafood consumption can be obtained, the estimated value will vary greatly contingent on the database. The concentration of mercury in

Table 3 Total mercury ( $\mathrm{T}-\mathrm{Hg}$ ) concentrations in red blood cells (RBC) and hair by quartile of estimated methylmercury $(\mathrm{MeHg})$ intake: 609 pregnant Japanese women enrolled in the Tohoku Study of Child Development

\begin{tabular}{|c|c|c|c|c|c|c|}
\hline \multirow[b]{2}{*}{ Quartile } & \multirow[b]{2}{*}{ MeHg intake ( $\mu \mathrm{g} /$ week) } & \multirow[b]{2}{*}{$n$} & \multicolumn{2}{|c|}{$\log [\mathrm{T}-\mathrm{Hg}$ in RBC $(\mathrm{ng} / \mathrm{g})]$} & \multicolumn{2}{|c|}{$\log [\mathrm{T}-\mathrm{Hg}$ in hair $(\mu \mathrm{g} / \mathrm{g})]$} \\
\hline & & & Mean & SD & Mean & SD \\
\hline 1 & $\leq 25 \cdot 5$ & 152 & $1 \cdot 01$ & 0.20 & 0.20 & 0.20 \\
\hline 2 & $>25 \cdot 5-42 \cdot 3$ & 152 & $1 \cdot 08$ & 0.20 & 0.27 & $0 \cdot 18$ \\
\hline 3 & $>42 \cdot 3-66 \cdot 8$ & 152 & $1 \cdot 16$ & 0.17 & 0.36 & $0 \cdot 18$ \\
\hline \multirow[t]{2}{*}{4} & $>66 \cdot 8$ & 153 & \multirow{2}{*}{\multicolumn{2}{|c|}{$\begin{array}{l}1.17 \quad 0.0001 \\
0.21\end{array}$}} & 0.35 & 0.21 \\
\hline & & & & & \multicolumn{2}{|c|}{$P<0.0001$} \\
\hline
\end{tabular}

$P$ values calculated by one-way ANOVA. 
fish depends on size, age and the surroundings of the fish ${ }^{(17)}$. To estimate the MeHg intake accurately, a more detailed database that has a sufficient number of samples and considers these factors of concentration variability will be needed.

In conclusion, the correlation coefficient between the estimated $\mathrm{MeHg}$ intake based on the FFQ and biomarkers was 'about $0 \cdot 3$ '. The accuracy of the estimated value was generally indicated because the association was statistically significant, and at a level similar to other studies ${ }^{(29,30)}$. Although the estimated value involves the uncertainties mentioned above, it appears that the FFQ is a useful tool for assessment of exposure to $\mathrm{MeHg}$.

\section{Acknowledgements}

Sources of funding: This study was supported by grants from the Ministry of Health, Labor and Welfare (Research on Risk of Chemical Substances) and the Ministry of Education, Culture, Sports, Science and Technology (Grant-in-Aid for Scientific Research [B]), Japan. Conflict of interest declaration: There are no conflicts of interest. Authorship responsibilities: K.Y.-S. and H.S. conceived the study design and supervised data analysis. K.N. and K.S. organized the data collection of the cohort study. M.S., T.O. and S.K. carried out the analysis of total mercury. N.K. gave advice about statistical analysis. Finally, K.Y.-S. wrote the manuscript and the other authors critically revised the manuscript. Acknowledgments: We thank all the participants of this study.

\section{References}

1. Grandjean P, Weihe P, White RF, Debes F, Araki S, Yokoyama K, Murata K, Sorensen N, Dahl R \& Jorgensen PJ (1997) Cognitive deficit in 7-year-old children with prenatal exposure to methylmercury. Neurotoxicol Teratol 19, $417-428$.

2. Crump KS, Kjellstorm T, Shipp AM, Silver A \& Stewart A (1998) Influence of prenatal mercury exposure upon scholastic and psychological test performance: benchmark analysis of a New Zealand cohort. Risk Anal 18, 701-713.

3. Murata K, Weihe P, Renzoni A, Debes F, Vasconcelos R, Zino F, Araki S, Jorgensen PJ, White R \& Grandjean P (1999) Delayed evoked potentials in children exposed to methylmercury from seafood. Neurotoxicol Teratol 21, 343-348.

4. Food and Agriculture Organization of the United Nations/ World Health Organization (2003) Joint FAO/WHO Expert Committee on Food Additives, Sixty-first meeting, Rome, 10-19 June 2003, Summary and conclusions. http://www. who.int/entity/ipcs/food/jecfa/summaries/en/summary_61. pdf (accessed September 2008).

5. US Environmental Protection Agency (2001) Integrated Risk Information System, Methylmercury (MeHg) (CASRN 22967-92-6). http://www.epa.gov/iris/subst/0073.htm (accessed September 2008).

6. US Department of Health and Human Services, Public Health Service, Agency for Toxic Substances and Disease Registry (1999) Toxicological profile for mercury. http://www.atsdr.cdc.gov/toxprofiles/tp46.pdf （accessed September 2008)

7. Japan Food Safety Commission Secretariat (2005) Food Safety Risk Assessment Related to Methylmercury in Seafood. http://www.fsc.go.jp/english/topics/methylmercury_risk_assessment.pdf (accessed September 2008).

8. World Health Organization (1990) Methylmercury. Environmental Health Criteria no. 101. Geneva: WHO.

9. Mouratidou T, Ford F \& Fraser RB (2006) Validation of a food-frequency questionnaire for use in pregnancy. Public Health Nutr 9, 515-522.

10. Segovia-Siapco G, Singh P, Jaceldo-Siegl K \& Sabate J (2007) Validation of a food-frequency questionnaire for measurement of nutrient intake in a dietary intervention study. Public Health Nutr 10, 177-184.

11. Hibbeln JR, Davis JM, Steer C, Emmett P, Rogers I, Williams C \& Golding J (2007) Maternal seafood consumption in pregnancy and neurodevelopmental outcomes in childhood (ALSPAC study): an observational cohort study. Lancet 369, 578-585.

12. Oken E, Radesky JS, Wright RO, Bellinger DC, Amarasiriwardena CJ, Kleinman KP, Hu H \& Gillman MW (2008) Maternal fish intake during pregnancy, blood mercury levels, and child cognition at age 3 years in a US cohort. Am J Epidemiol 167, 1171-1181.

13. Nakai K, Suzuki K, Oka T et al. (2004) The Tohoku Study of Child Development: a cohort study of effects of perinatal exposures to methylmercury and environmentally persistent organic pollutants on neurobehavioral development in Japanese children. Tohoku J Exp Med 202, 227-237.

14. Date C, Yamaguchi M \& Tanaka H (1996) Development of a food frequency questionnaire in Japan. J Epidemiol 6, Suppl. 3, S131-S136.

15. The Japan Ministry of Health, Labor and Welfare (2005) Mercury concentrations in seafood. http://www-bm.mhlw. go.jp/shingi/2005/08/dl/s0812-3a1.pdf (accessed September 2008).

16. Honda S, Hylander L \& Sakamoto M (2006) Recent advances in evaluation of health effects on mercury with special reference to methylmercury - a minireview. Environ Health Prev Med 11, 171-176.

17. Food and Agriculture Organization of the United Nations/ World Health Organization (2004) Safety evaluation of certain food additives and contaminants. WHO Food Additives Series: 52. Prepared by the Sixty-first meeting of the Joint FAO/WHO Expert Committee on Food Additives (JECFA). http://whqlibdoc.who.int/publications/2004/924166052X.pdf\# search $=$ 'Safety $\% 20$ evaluation $\% 20$ of $\% 20$ certain $\% 20$ food $\% 20$ additives\%20and\%20contaminants' (accessed September 2008).

18. Berglund M, Lind B, Björnberg KA, Palm B, Einarsson Ö \& Vahter M (2005) Inter-individual variations of human mercury exposure biomarkers: a cross-sectional assessment. Environ Health 4, 20.

19. Yamamoto R \& Suzuki T (1978) Effects of artificial hairwaving on hair mercury values. Int Arch Occup Environ Health 42, 1-9.

20. Dakeishi M, Nakai K, Sakamoto M et al. (2005) Effects of hair treatment on hair mercury - the best biomarker of methylmercury exposure? Environ Health Prev Med 10, 208-212.

21. Ohba T, Kurokawa N, Nakai K, Shimada M, Suzuki K, Sugawara N, Kameo S, Satoh C \& Satoh H (2008) Permanent waving does not change mercury concentration in the proximal segment of hair close to scalp. Tohoku J Exp Med 214, 69-78.

22. Akagi H \& Nishimura H (1991) Specification of mercury in the environment. In Advances in Mercury Toxicology, pp. 3-76 [T Suzuki, I Nobumasa and TW Clarkson, editors]. New York: Plenum Press. 
23. Food and Agriculture Organization of the United Nations (2008) FAOSTAT. http://faostat.fao.org/site/291/default.aspx (accessed September 2008).

24. Davidson PW, Myers GJ, Cox C et al. (1998) Effects of prenatal and postnatal methylmercury exposure from fish consumption on neurodevelopment: outcomes at 66 months of age in the Seychelles Child Development Study. JAMA 280, 701-707.

25. Myers GJ, Davidson PW, Cox C et al. (2003) Prenatal methylmercury exposure from ocean fish consumption in the Seychelles child development study. Lancet 361, 1686-1692.

26. Myers GJ, Davidson PW \& Strain JJ (2007) Nutrient and methyl mercury exposure from consuming fish. J Nutr 137, 2805-2808.

27. Bonham MP, Duffy EM, Wallace JMW, Robson PJ, Myers GJ, Davidson PW, Clarkson TW, Shamlaye CF \& Strain JJ (2008) Habitual fish consumption does not prevent a decrease in LCPUFA status in pregnant women (the Seychelles Child Development Nutrition Study). Prostaglandins Leukot Essent Fatty Acids 78, 343-350.

28. Mahaffey KR (2004) Fish and shellfish as dietary sources of methylmercury and the $\omega-3$ fatty acids, eicosahexaenoic acid and docosahexaenoic acid: risks and benefits. Environ Res 95, 414-428.

29. Sanzo JM, Dorronsoro M, Amiano P, Amurrio A, Aguinagalde FX \& Azpiri MA (2001) Estimation and validation of mercury intake associated with fish consumption in an EPIC cohort of Spain. Public Health Nutr 4, 981-988.

30. Iwasaki Y, Sakamoto M, Nakai K, Oka T, Dakeishi M, Iwata T, Satoh H \& Murata K (2003) Estimation of daily mercury intake from seafood in Japanese women: Akita CrossSectional Study. Tohoku J Exp Med 200, 67-73.

31. Ohno T, Sakamoto M, Kurosawa T, Dakeishi M, Iwata T \& Murata K (2007) Total mercury levels in hair, toenail, and urine among women free from occupational exposure and their relations to renal tubular function. Environ Res $\mathbf{1 0 3}$, 191-197.

32. Tsubono Y \& Hisamichi S (2001) Nutritional Epidemiology. Tokyo: Nankodo Press.

33. Yamamoto I, Matsuda K \& Sato C (1990) Contents of Heavy Metals in Seafood Along the Coast of Hokkaido. Sapporo: Hokkaido Institute of Public Health.

34. Nakagawa R, Yumita Y \& Hiromoto M (1997) Total mercury intake from fish and shellfish. Chemosphere $\mathbf{3 5}$, 2909-2913. 